\title{
Midline Spinal Cord Hamartomas-A Report of Six Cases
}

\author{
Damera Naveen Chandra Rao, Vallabhaneni Kalyan Chakravarthy, Eslavath Aruna, \\ Gundala Venkata Ratnam, Diddi Ranga Rao
}

Department of Pathology, Pinnamaneni Siddhartha Institute of Medical Sciences \& Research Foundation, Chinna Avutapalli, India. Email: naveendr18@yahoo.com

Received April 6 ${ }^{\text {th }}, 2013$; revised May 10 ${ }^{\text {th }}, 2013$; accepted May 22 ${ }^{\text {nd }}, 2013$

Copyright (c) 2013 Damera Naveen Chandra Rao et al. This is an open access article distributed under the Creative Commons Attribution License, which permits unrestricted use, distribution, and reproduction in any medium, provided the original work is properly cited.

\begin{abstract}
Midline Spinal Cord Hamartomas are relatively rare and asymptomatic. These lesions may present with a tethered cord and a normal overlying skin, a skin dimple, a dermal sinus tract or dense collagen. Most patients have few or no neurological symptoms related to them. Microscopically they are composed of mature and well-differentiated ectodermal and mesodermal elements, meningothelial cells, calcification, and even urothelium. We report MRI and histologic features of midline spinal cord hamartomas in six cases.
\end{abstract}

Keywords: Hamartoma; Meningothelial Cells; Ectodermal

\section{Introduction}

Midline Spinal Cord Hamartomas are relatively rare \& asymptomatic than the common congenital spinal masses which include lipomas, epidermoid cysts, dermoid cysts, and teratomas [1]. Midline Spinal Cord Hamartomas are not related to brain malformations or neurofibromatosis, and most patients have few or no neurological symptoms related to them [2]. These lesions may present with a tethered cord \& a normal overlying skin, a skin dimple, a dermal sinus tract, cutaneous angioma or dense collagen [3]. Microscopically these are composed of only ectodermal and mesodermal, mature and well-differentiated elements, meningothelial cells, calcification, and even urothelium [2,3].

Surgery is often done to relieve the neurological symptoms due to tethering of the cord [4,5]. We report 6 cases of Spinal Cord Hamartomas with tethered cord.

\section{Material and Methods}

6 cases of Spinal Cord Hamartoma associated with tethered cord were encountered out of 156 neurosurgical specimens received in our institute during the last 3 yrs. (01-01-09 to 31-12-11). We have collected complete clinical data, investigations including MRI and examined all the six cases grossly and histologically in detail. We also used special stains and markers where necessary. The details of the cases are presented herewith.
Case 1: A 15-year-old boy presented with urine \& fecal incontinence since birth. MRI showed Bifid L5, sacro-coccygeal dysplasia \& a tethered cord at L5 with a fatty mass compressing filum terminale which was excised (Figure 1). Grossly the mass was a $5 \mathrm{~cm}$ soft tissue. On cut section fibro fatty tissue with fibrous streaks seen. Microscopically it was a non capsulate hamartoma, of fat, skeletal muscle, collagen and with a fragment of urothelium (Figure 2).

Case 2: A 10-day boy presented with a 2 cm discolouration of skin suggestive of a nevus and a dermal sinus at S1 area with no bony deficit (Figure 3). Surgery showed a subcutaneous mass of $3 \mathrm{cms}$ soft tissue with a tethered cord at S1 area, which on microscopy showed a fibrofatty hamartoma of collagen \& fat (Figure 4).

Case 3: A 10-month boy had a soft swelling at lumbosacral area since birth. MRI showed a spinal dysraphism at L4. A $7 \mathrm{~cm}$ skin covered mass with a central small bony structure of $0.6 \mathrm{~cm}$ and a tethered cord was excised (Figure 5). On cut section fibro fatty tissue with fibrous streaks seen. Histology showed a benign osteolipoma (Figure 6).

Case 4: A 4-month-old girl with right Club foot and progressive weakness of legs since last 2 months. MRI showed spina bifida at L5 and a tethered cord with an attached $9 \mathrm{cms}$ capsulate mass (Figure 7). The mass was excised and histology showed a lipoma with a few nerve fibers attached to its surface (Figure 8). 


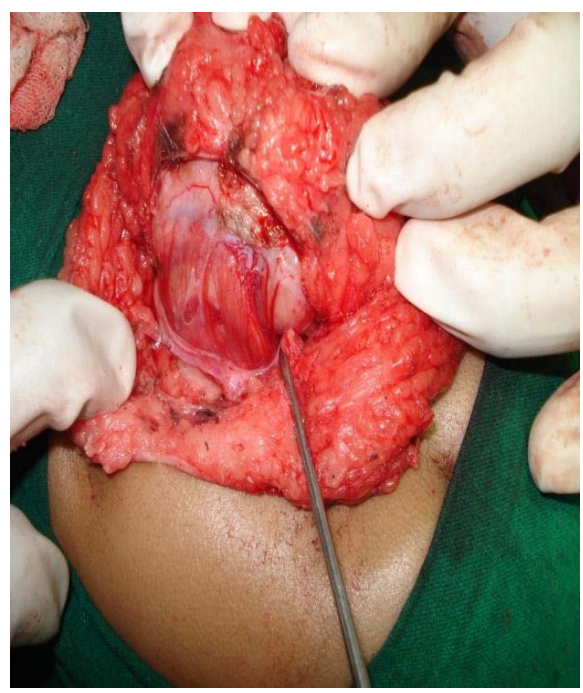

Figure 1. A tethered cord at L5 with a fatty mass compressing filum terminal.

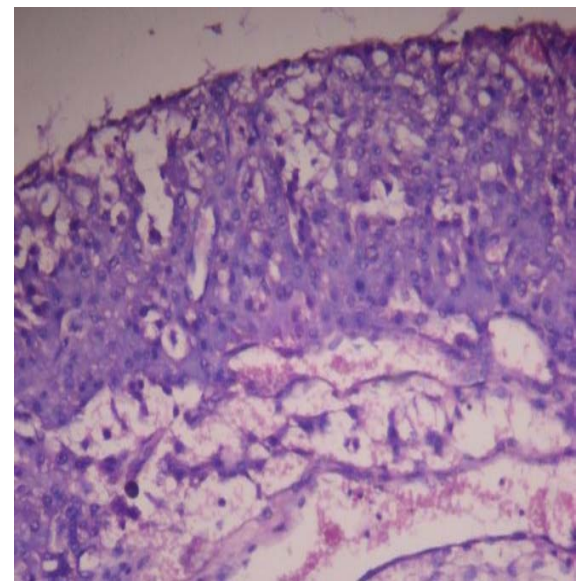

Figure 2. Microscopy showing non capsulate hamartoma of fat, skeletal muscle, collagen \& a fragment of urothelium. $10 \times 10$ H \& E.

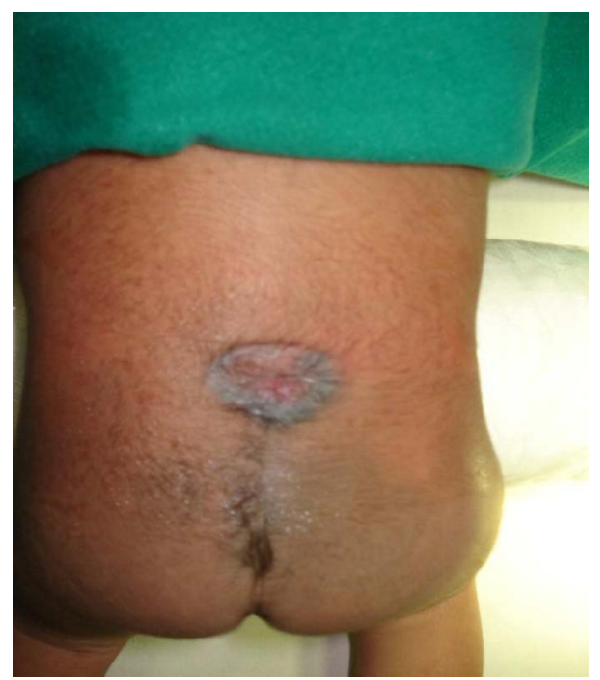

Figure $3.2 \mathrm{~cm}$ nevus with dermal sinus at $\mathrm{S} 1$ area.

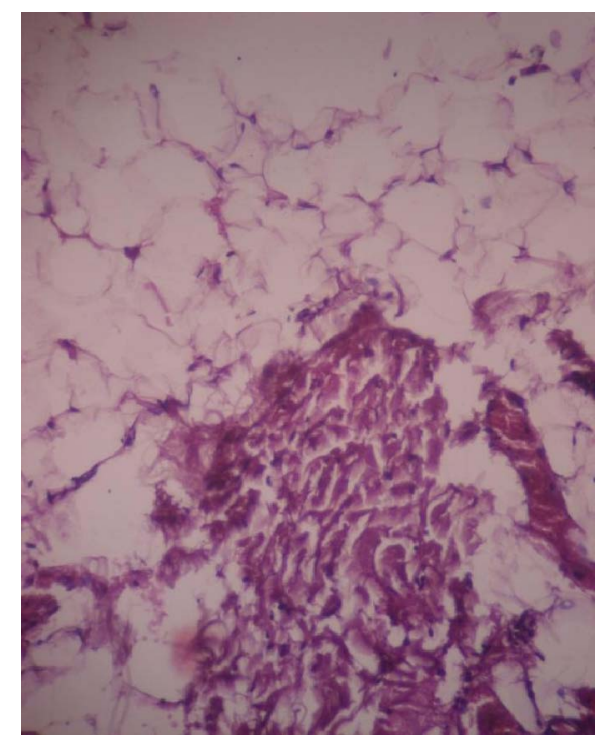

Figure 4. Microscopy showing fibrofatty hamartoma of collagen \& fat. $10 \times 10 \mathrm{H} \& \mathrm{E}$.

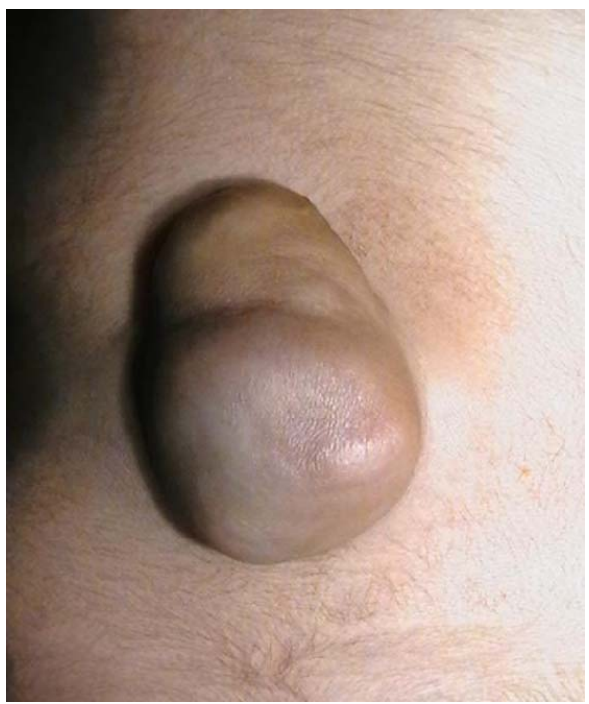

Figure $5.7 \mathrm{cms}$ skin covered mass with a central small bony structure of $0.6 \mathrm{~cm}$ size at lumbosacral area since birth.

Case 5: A 7-year-old boy, with urine \& fecal incontinence since birth had a swelling of $3 \mathrm{cms}$ at sacral area since birth. MRI showed a bony deficit measuring 0.25 $\mathrm{cm}$ noted in S2 with a tethered cord beneath the mass. A polypoid mass of $3 \mathrm{cms}$ composed of collagen extending to deep surgical margin was received (Figure 9).

Histology showed haphazard cords of meningothelial cells \& Psammoma bodies in collagenous tissue (Figure 10).

Case 6: A 55-year-old lady presented with weakness of left leg, a hyperpigmentation at L3 - L4 area and a non healing ulcer at natal cleft (Figure 11). A partly cystic lesion at D12 - L2 \& a tethered cord were seen \& excised. The specimen was received in multiple fragments. His- 


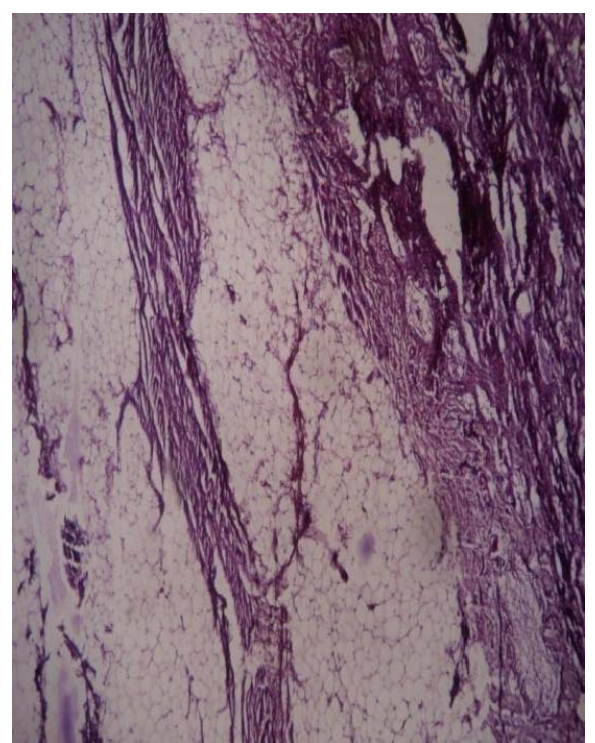

Figure 6. Microscopy showed a benign osteolipoma $10 \times 10$ H \& E.

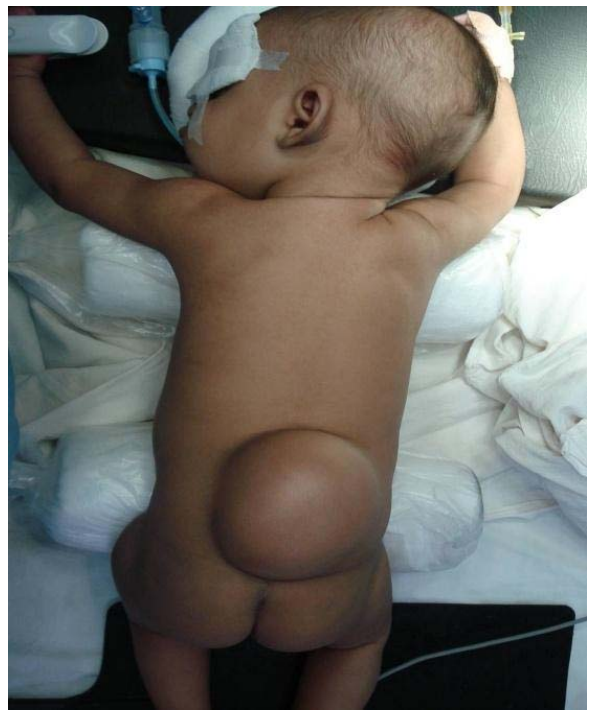

Figure 7. A spina bifida at L5 \& a tethered cord with attached 9 cms capsulate mass.

tology showed an epidermal cyst with focal calcification of collagen in the wall (Figure 12).

\section{Discussion}

Spinal Hamartomas are extremely rare lesions in children. Occurring usually intracranially and very rarely in the spine $[1,3,6]$. In our study age ranged from 10-day old child to 55-year-old lady of which $83 \%$ being in children. With M:F being 2:1. Midline spinal hamartomas may present with a skin dimple, cutaneous angioma, subcutaneous mass, or normal overlying skin $[7,8]$. We encountered two cases with hyperpigmented skin along with a dermal sinus, while others had a normal overlying skin.

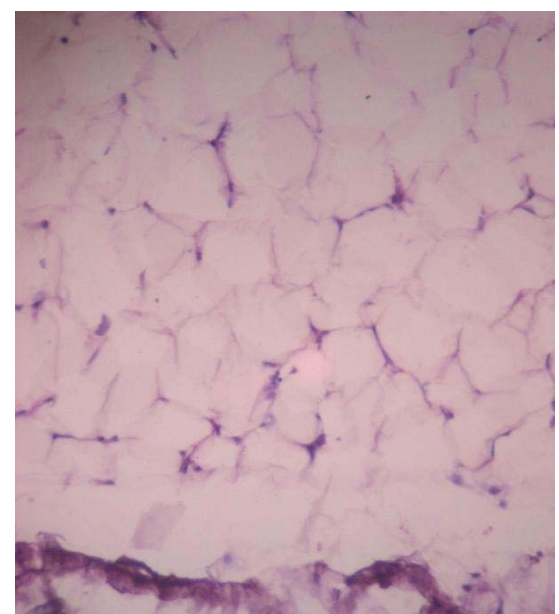

Figure 8. Microscopy showed a lipoma with a few nerve fibres attached to its surface. $10 \times 10 \mathrm{H} \& \mathrm{E}$.

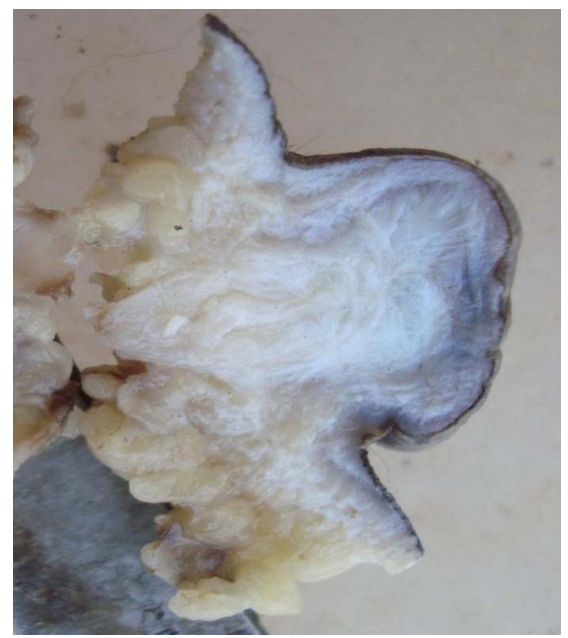

Figure 9. A polypoid mass of $3 \mathrm{cms}$ composed of collagen extending to deep surgical margin.

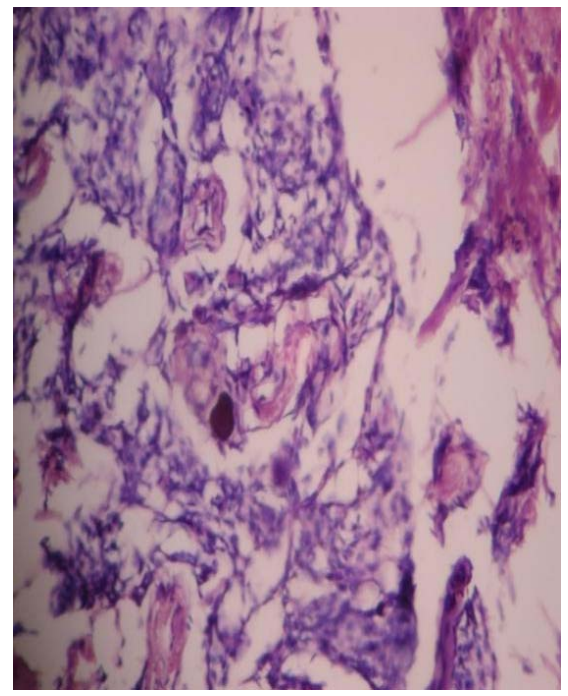

Figure 10. Microscopy showed haphazard cords of meningothelial cells \& Psammoma bodies. 10 × 10 H \& E. 


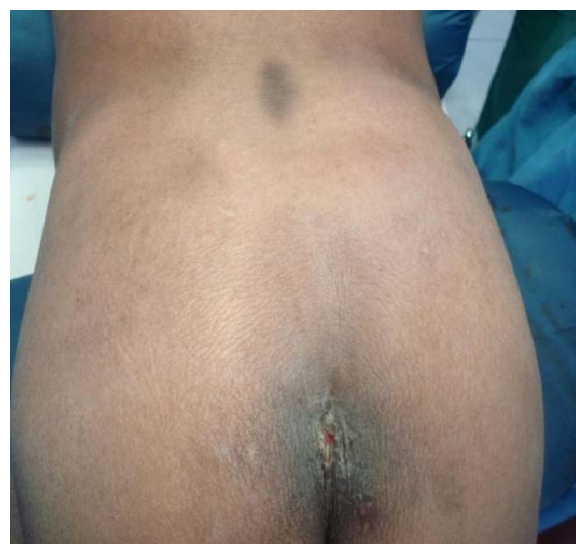

Figure 11. A hyperpigmentation at L3 - L4 area \& a non healing ulcer at natal cleft.

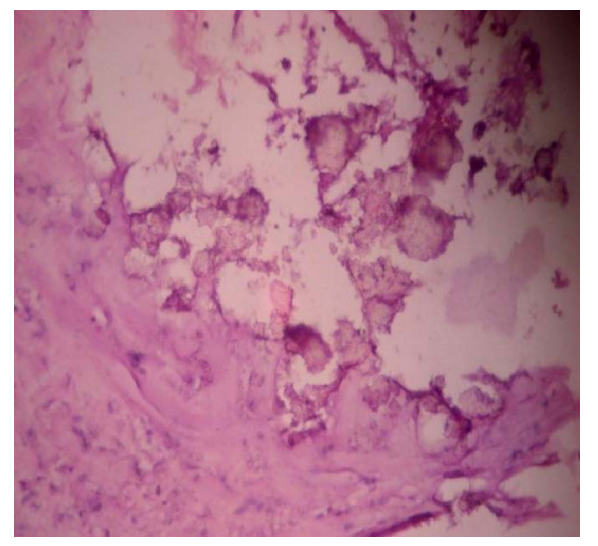

Figure 12. Microscopy showed an epidermal cyst with focal calcification of collagen in the wall. $10 \times 10 \mathrm{H} \& \mathrm{E}$.

Spinal hamartomas may be located in the thoracic, lumbar, and sacral region or at the junction between these segments [3,9]. In the present study all the patients had a midline lesion in the lumbosacral area. Ranging from D12 to S2.

Midline spinal hamartomas are not associated with hydrocephalous, Chiari malformations, or open spinal dysraphisms [10,11]. Our study showed following malformations along with hamartoma, bifid L5, sacrococcygeal dysplasia, spinal dysraphism at L4, spina bifida at L5, bony defect in the sacral area and partly cystic lesion at D12 - L2, all were closed spinal defects.

According to the existing literature, most patients with spinal hamartomas are neurologically intact at the time of presentation [3,12].

Although hamartomas may cause no initial symptoms, but as growth proceeds and spinal cord rises, there may be traction due to its being tethered to the cord $[3,13]$.

In the present study all 6 cases had tethered cord of which four cases had neurological symptoms ranging from weakness of lower limbs, club foot, urine and fecal incontinence. One case had a dermal sinus, one case was asymptomatic.
Spinal tumorous lesions associated with spinal dysraphism have been traditionally described as lipoma since they are composed mostly of fatty tissue and are different from lipomas arising in other part of the body in that they often contain various tissues of ecto- and mesodermal origin such as nerves, fat, muscle tissue, cartilage, bone, abnormal vessels, glands, synovial membranes, lymphoid tissues, and even urinary tract tissue $[3,6,8$, $14,15]$. Although they are also similar to teratoma, it is generally accepted that they are malformative lesions which lack neoplastic potential and elements from all the three germ layers and therefore should be diagnosed as hamartoma rather than lipoma or teratoma $[8,11,14]$.

In our study the cases there were non capsulate hamartomas composed of fat, skeletal muscle, bone, collagen, a fragment of urothelium, meningeal cells \& Psammoma bodies and an epidermal cyst with focal calcification of collagen in the wall.

The mechanism for the formation of spinal hamartomas is not clear 5. The neural tube separates from the overlying ectoderm by the process of disjunction, sometimes between 3 to 8 weeks of gestation. Incomplete disjunction between them may result in the formation of dermal sinus tract $[5,15,16]$.

This exposed neural tissue from the spinal dysraphism may stimulate aberrant differentiation of overlying mesodermal precursors, inducing disordered proliferation of fat, collagen, and muscle tissue [12,13]. Symptomatic hamartomas of the spinal cord have been associated with neurofibromatosis type-I, spinal giant cell angioblastomas, spinal dysraphism and Proteus syndrome. Spinal hamartomas are localized masses, but very rarely the mass can have both extradural and intradural components including even certain amount of intramedullary growth.

\section{Conclusion/Summary}

Midline spinal cord hamartomas are rare benign lesions which may be composed of neural tissue, fat, muscle tissue, cartilage, bone, abnormal vessels, glands, synovial membranes, lymphoid tissues, and even urinary tract tissues. We suggest that, if a tell tale nevus or mass is seen in the lumbar area, the possibility of a tethered cord with or without a hamartoma is always to be excluded, irrespective of age of the patient, as in our case No. 6 . These benign lesions may become symptomatic and require neurosurgical intervention. Surgery is usually performed to prevent neurologic damage resulting from tethering of the cord, to prevent infection, and to correct a cosmetic defect.

\section{REFERENCES}

[1] T. J. Abel, A. Chowdhary, G. Jallo, P. P. Wang, P. Burger and A. M. Avellino, "Thoracic Spinal Cord Compression 
by Intramedullary Hamartomatous Tissue in a Young Boy," Case Report Neurosurgery, Vol. 62, No. 6, 2008, pp. E1380- E1381. doi:10.1227/01.neu.0000333314.40920.5e

[2] H.-C. Lin, C.-P. Yu, M.-Y. Liu and H.-S. Lee, “A Spinal Hamartoma in an Aged Woman,” The Kaohsiung Journal of Medical Sciences, Vol. 27, No. 7, 2009, pp. 295-298. doi:10.1016/j.kjms.2010.09.007

[3] S. Gupta, A. Kumar, A. N. Gangopadhyay and M. Kumar, "Spinal Cord with Pseudopancreatic Cyst," Indian Journal of Paediatrics, Vol. 75, No. 3, 2008, pp. 279-282. doi:10.1007/s12098-008-0060-3

[4] B. M. Hjermstad and E. B. Helwig, "Tailgut Cysts: Report of 53 Cases," American Journal of Clinical Pathology, Vol. 89, No. 2, 1988, pp. 139-147.

[5] E. Mendel, G. B. Lese, I. Gonzalez-Gomez, M. D. Nelson and C. Raffel, "Isolated Lumbosacral Neurenteric Cyst with Partial Sacral Agenesis: Case Report,” Neurosurgery, Vol. 35, 1994, pp. 1159-1162. doi:10.1227/00006123-199412000-00023

[6] L. S. Williams, A. M. Rojiani, R. G. Quisling and J. P. Mickle, "Retrorectal Cyst-Hamartomas and Sacral Dysplasia: MR Appearance,” American Journal of Neuroradiology, Vol. 19, No. 6, 1998, pp. 1043-1045.

[7] A. Maitra and V. Kumar, "Diseases of Infancy and Childhood,” In: V. Kumar, N. Fausto and A. Abbas, Eds., Robbins and Cotran, Robbins and Cotran Pathologic Basis of Disease, 8th Edition, Elsevier, Philadelphia, 2010, p. 498. doi:10.1016/B978-1-4377-0792-2.50015-8

[8] N. J. White, D. D. Cochrane and R. Beauchamp, "Paraparesis Caused by an Angiomatous Hamartoma in an Adolescent with Proteus Syndrome and Scoliosis,” Journal of Neurosurgery, Vol. 103, 2005, pp. 282-284.

[9] S. Yano, K. Hida, K. Nagashima and Y. Iwasaki, “Spinal
Fibrous Hamartomas of Infancy: Case Report,” Journal of Neurosurgery, Vol. 55, No. 3, 2004, p. 712. doi:10.1227/01.NEU.0000134614.73236.A4

[10] H. J. S. Bining, G. Saigal, R. S. Goswami, et al., "Spinal Hamartoma in a Neonate: Unusual Presentation and MR Imaging Findings," American Journal of Neuroradiology, Vol. 27, 2006, pp. 810-812.

[11] M. Castillo, M. M. Smith and D. Armao, "Midline Spinal Cord Hamartomas: MR Imaging Features of Two Patients,” American Journal of Neuroradiology, Vol. 20, No. 6, 1999, pp. 1169-1171.

[12] D. F. Morris, K. Murphy, L. B. Rorke, et al., "Spinal Hamartomas: A Distinct Clinical Entity,” Journal of Neurosurgery, Vol. 88, No. 6, 1998, pp. 954-961. doi:10.3171/jns.1998.88.6.0954

[13] G. Khanna, K. Mishra, S. Agarwal and S. Sharma, "Congenital Spinal Lipomas-Tumor versus Hamartomas," Indian Journal of Pediatrics, Vol. 66, No. 6, 1999, pp. 940-944. doi:10.1007/BF02723873

[14] K. Riley, C. A. Palmer, A. B. Oser, et al., "Spinal Cord Hamartoma: Case Report,” Neurosurgery, Vol. 44, No. 5, 1999, pp. 1125-1128. doi:10.1097/00006123-199905000-00109

[15] S. C. Lee, Y. S. Chun, S. E. Jung, K. W. Park and W. K. Kim, "Currarino Triad: Anorectal Malformation, Sacral Bony Abnormality, and Presacral Mass-A Review of 11 Cases,” Journal of Pediatric Surgery, Vol. 32, No. 5, 1997, pp. 8-61.

[16] A. L. Johnson, P. R. Ros and B. M. Hjermstad, "Tailgut Cysts: Diagnosis with CT and Sonography,” American Journal of Roentgenology, Vol. 147, No. 6, 1986, pp. 13091311. doi:10.2214/ajr.147.6.1309 